\title{
EDXRF for screening micronutrients in lentil and sorghum biofortification breeding programs
}

\author{
Georgia E. Guild (D) James C. R. Stangoulis 1
}

Received: 15 November 2020 / Accepted: 15 March 2021 / Published online: 27 March 2021

(C) The Author(s) 2021

\begin{abstract}
Background and aims This study explores the use of energy dispersive $\mathrm{x}$-ray fluorescence (EDXRF) for screening micronutrient concentrations in lentil and sorghum grain for biofortification breeding programs.

Methods Lentil and sorghum seed was provided from biofortification breeding programs and analysed with inductively coupled plasma mass spectrometry (ICP$\mathrm{MS}$ ) to determine the reference concentration levels of $\mathrm{Ca}, \mathrm{Mn}, \mathrm{Fe}, \mathrm{Cu}$ and $\mathrm{Zn}$. A subset of these samples was used to establish the EDXRF calibration and another subset used for validation of the method.

Results The results show the EDXRF analyses of the lentil and sorghum are not significantly different to the reference ICP-MS for all elements analysed, except for Mn with \%RSD of replicate analysis $<5 \%$ for lentil analysis and $<10 \%$ for sorghum.

Conclusions EDXRF analysis enables rapid and accurate analysis of $\mathrm{Ca}, \mathrm{Mn}, \mathrm{Fe}, \mathrm{Cu}$ and $\mathrm{Zn}$ in lentil and sorghum.
\end{abstract}

Keywords XRF $\cdot$ EDXRF $\cdot$ Biofortification . Micronutrient · Plant

Responsible Editor: Matthias Wissuwa.

G. E. Guild $(\bowtie) \cdot J$. C. R. Stangoulis

College of Science \& Engineering, Flinders University, GPO Box 2100, Adelaide, South Australia 5001, Australia

e-mail: Georgia.Guild@ flinders.edu.au

J. C. R. Stangoulis

e-mail: James.Stangouils@ flinders.edu.au

\section{Introduction}

Worldwide, more than 2 billion people, including at least 340 million children, suffer from micronutrient deficiencies (UNICEF 2020). A diverse diet should provide adequate nutrients, however for many people in developing countries a diet rich in nutrient dense meat, fruit and vegetables is either not available or affordable (Bouis et al. 2011). Calorie-dense and often nutrient-poor crops such as maize, rice and wheat are staple foods for many of the world's poorest, leading to the prevalence of micronutrient malnutrition (Bouis and Saltzman 2017). Ongoing programs are required to ensure sufficient nutrient intake to eliminate these deficiencies (Gorstein et al. 2007). Biofortification is one such approach which focusses on increasing the micronutrient concentration in crops through conventional plant breeding and agronomic approaches (Pfeiffer and McClafferty 2007). The HarvestPlus program has focussed on increasing iron ( $\mathrm{Fe})$, zinc $(\mathrm{Zn})$ and provitamin A carotenoids in staple crops and has released more than 150 biofortified varieties (Bouis and Saltzman 2017).

Elemental analysis is a vital part of the biofortification breeding program as this identifies genotypes with elevated levels of micronutrients. Conventionally, wet-chemistry techniques such as atomic absorption spectroscopy (AAS) and inductively coupled plasma optical emission or mass spectrometry (ICPOES, ICP-MS) are commonly used. These techniques are well established and produce accurate analyses, however they require extensive sample preparation prior 
to analysis. Samples need to be dried and in some cases ground, and then followed by accurate weighing and acid-digestion prior to dilution and analysis. These steps require the use of high purity reagents, well-equipped laboratories and highly trained staff to ensure accurate and precise results and consequently they can be time consuming and expensive.

We have previously shown the application of energy dispersive $\mathrm{x}$-ray fluorescence (EDXRF) analysis for screening in the HarvestPlus focus crops, specifically wheat (Paltridge et al. 2012a), rice, pearl millet (Paltridge et al. 2012b), maize and bean (Guild et al. 2017). EDXRF has also been shown as a successful screening technique for the HarvestPlus secondary crops cowpea (Guild et al. 2017) and potato (Sosa et al. 2018). The work presented here will complete the series with the final crops in the HarvestPlus breeding program; lentil (lens culinaris) and sorghum (sorghum bicolor).

Within lentil and sorghum biofortification breeding programs, screening is required to identify those genotypes high in $\mathrm{Fe}$ and/or $\mathrm{Zn}$. The target levels for Fe and $\mathrm{Zn}$ in lentil and sorghum breeding programs are $70 \mathrm{mg}$ $\mathrm{kg}^{-1} \mathrm{Fe}$ in lentils and $60 \mathrm{mg} \mathrm{kg}^{-1} \mathrm{Fe}$ and $32 \mathrm{mg} \mathrm{kg}^{-1} \mathrm{Zn}$ in sorghum (HarvestPlus 2014). We have previously shown in other crops that EDXRF is the ideal tool for this analysis across the HarvestPlus program, enabling results comparable with ICP-MS but with the benefit of minimal sample preparation, non-destructive rapid analysis, low consumable costs and user-friendly techniques. Here we aim to confirm that the EDXRF technique can also be used to determine the concentration of primary biofortification target elements $\mathrm{Fe}$ and $\mathrm{Zn}$ simultaneously with other nutritionally essential minerals $\mathrm{Ca}, \mathrm{Mn}$ and $\mathrm{Cu}$ (Welch and Graham 2005).

\section{Methods}

Grain samples

Lentil and sorghum calibration standards suitable for elemental analysis are not commercially available. Consequently, a set of calibration and validation samples were acquired for each of the crops from collaborators within the HarvestPlus program. Samples were prepared as per HarvestPlus protocols (Stangoulis and Sison 2008) to ensure minimal contamination due to dust and plant material. Lentil samples were provided from Bangladesh
Agricultural Research Institute (BARI) and International Center for Agricultural Research in the Dry Areas (ICARDA) and sorghum samples from International Crops Research Institute for the Semi-Arid Tropics (ICRISAT). Sorghum samples were separated into white and red to determine if there was any variation in analytical response to seed coat colour. All seed samples were sterilised by gamma irradiation ( $50 \mathrm{kGray}$ ) prior to release into Australia. To generate robust reference values for the seed samples, duplicate ICP-MS analysis was carried out at Flinders University using a closed tube digestion (Knez et al. 2018; Wheal et al. 2011). Briefly, $\sim 0.2 \mathrm{~g}$ of dried (whole) seed was accurately weighed and digested with nitric acid and hydrogen peroxide solution and heated at $80{ }^{\circ} \mathrm{C}$ for $30 \mathrm{~min}$. Tubes were subsequently vented and then heated at $125^{\circ} \mathrm{C}$ for a further $120 \mathrm{~min}$. Internal standard was added to the digested solutions and diluted 10 fold with $40 \% \mathrm{HNO}_{3}$.

\section{EDXRF}

EDXRF analyses were acquired using the Bruker S2 Puma EDXRF fitted with a 20-position sample tray. Acquisition parameters are summarised in Table 1. As previously reported (Guild et al. 2017; Paltridge et al. 2012a; Paltridge et al. 2012b) samples were analysed in supplied sample cups sealed on one end with $4 \mu \mathrm{m}$ Poly-4 XRF film and all samples were analysed with $>5 \mathrm{~g}$ of lentil or sorghum to ensure "infinite thickness" (Paltridge et al. 2012b). All EDXRF measurements reported here are from the analysis of whole seeds.

Statistics

The calibration and validation statistics are defined below (Perring and Andrey 2003).

Concentration determined by ICP-MS

Concentration determined by EDXRF

$y_{i}$

Bias

$\widehat{y_{i}}$

$\frac{\sum_{i=1}^{n}\left(\widehat{y_{i}}-y_{i}\right)}{n}$

Standard error of prediction (SEP)

$\sqrt{\frac{\sum_{i=1}^{n}\left(\widehat{y_{i}}-y_{i}\right)^{2}}{n}}$

Standard error of calibration (SEC)

$$
\sqrt{\frac{\sum_{i=1}^{n}\left(\widehat{y_{i}}-y_{i}\right)^{2}}{n-p-1}}
$$


Table 1 EDXRF analysis conditions

* $\mathrm{Ca}$ and $\mathrm{Fe} \mathrm{K} \alpha$ lines $\mathrm{K} \beta$ overlap respectively corrected for $\mathrm{K}$ and $\mathrm{Mn}$

\begin{tabular}{ll}
\hline Atmosphere & Air \\
X-ray tube & Palladium \\
Voltage & $40 \mathrm{kV}$ \\
Current & $240 \mu \mathrm{A}$ \\
Peak Detected & $\mathrm{K} \alpha^{*}$ \\
Acquisition time & $30 \mathrm{~s}$ \\
Tube Filter & $\mathrm{Al}(500 \mu)$ \\
Detector & $\mathrm{SDD}$ \\
\hline
\end{tabular}

\section{Results}

Calibration

An EDXRF calibration was established for each crop consisting of 37 lentil and 41 sorghum samples. The calibration data showed a strong correlation between EDXRF intensity and the ICP-MS reference analysis with $\mathrm{r}^{2}>0.88$ for all elements in both crops (Table 2; Fig. 1). The calibration statistics (Table 2) show the standard error of calibration (SEC) was $< \pm 5 \mathrm{mg} \mathrm{kg}^{-1}$ for all elements in both crops with the exception of $\mathrm{Ca}( \pm 41.86$ and $\pm 15.89 \mathrm{mg} \mathrm{kg}^{-1}$ for lentil and sorghum respectively). The limits of quantification are reported in Table 2 and confirm this technique is suitable for high throughput screening in biofortification breeding programs. A combination of red and white sorghum seed was used for the final calibration as no significant matrix effect due to colour was observed (Fig. 2).
Validation

Validation of the calibration methods were determined with the analysis of 37 lentil and 38 sorghum samples with a range of each of the elements of interest. A strong correlation between the EDXRF results and the robust ICP-MS analysis was shown for all elements in both crops $\left(r^{2}>0.8\right)$ as shown in Fig. 3. EDXRF reproducibility was determined from duplicate analysis of the validation samples and showed variability between replicates of $<6 \%$ for all elements in lentil and $<10 \%$ in all elements in sorghum. As shown in Tables 3 and 4, the average bias between XRF and ICP-MS analysis was less than $1.3 \mathrm{mg} \mathrm{kg}^{-1}$ for all elements in both crops with the exception of $\mathrm{Ca}$ and not significantly different from zero (paired t-test $\mathrm{p}>0.05$ for all elements except Mn).

\section{Discussion}

The focus of this EDXRF method is rapid screening for elements of interest within lentil and sorghum biofortification breeding programs. The predominant elements of interest within these programs are $\mathrm{Fe}$ and $\mathrm{Zn}$ due to their essentiality and benefits for human health and nutrition. Other elements that are beneficial to human health include $\mathrm{Ca}, \mathrm{Mn}$ and $\mathrm{Cu}$ (Welch and Graham 2005) and these elements can also be detected with EDXRF. The benefit of EDXRF is the ability to analyse multiple elements simultaneously (as shown in

Table 2 Statistics for lentil and sorghum calibrations

\begin{tabular}{|c|c|c|c|c|c|c|}
\hline Species & Element & $\begin{array}{l}\text { Range } \\
\left(\mathrm{mg} \mathrm{kg}^{-1}\right)\end{array}$ & $\begin{array}{l}\text { Mean } \\
\left(\mathrm{mg} \mathrm{kg}^{-1}\right)\end{array}$ & $r^{2}$ & $\begin{array}{l}\text { SEC } \\
\left(\mathrm{mg} \mathrm{kg}^{-1}\right)\end{array}$ & $\begin{array}{l}\text { LOQ } \\
\left(\mathrm{mg} \mathrm{kg}^{-1}\right)\end{array}$ \\
\hline \multirow[t]{5}{*}{ Lentil } & $\mathrm{Ca}$ & $470-1170$ & 722.7 & 0.95 & \pm 41.9 & 42.0 \\
\hline & $\mathrm{Mn}$ & $10.0-27.0$ & 17.1 & 0.89 & \pm 1.3 & 3.8 \\
\hline & $\mathrm{Fe}$ & $49.0-123.0$ & 81.2 & 0.95 & \pm 4.5 & 4.6 \\
\hline & $\mathrm{Cu}$ & $8.8-21.0$ & 12.6 & 0.95 & \pm 0.7 & 2.0 \\
\hline & $\mathrm{Zn}$ & $38.0-106.0$ & 61.4 & 0.98 & \pm 2.7 & 1.5 \\
\hline \multirow[t]{5}{*}{ Sorghum } & $\mathrm{Ca}$ & $74.3-240.0$ & 144.4 & 0.88 & \pm 15.9 & 32.2 \\
\hline & $\mathrm{Mn}$ & $11.6-37.3$ & 20.4 & 0.92 & \pm 2.2 & 6.8 \\
\hline & $\mathrm{Fe}$ & $23.0-57.1$ & 44.9 & 0.93 & \pm 2.2 & 7.7 \\
\hline & $\mathrm{Cu}$ & $1.5-9.7$ & 4.44 & 0.95 & \pm 0.5 & 1.5 \\
\hline & $\mathrm{Zn}$ & $19.6-71.2$ & 38.8 & 0.94 & \pm 2.8 & 1.6 \\
\hline
\end{tabular}



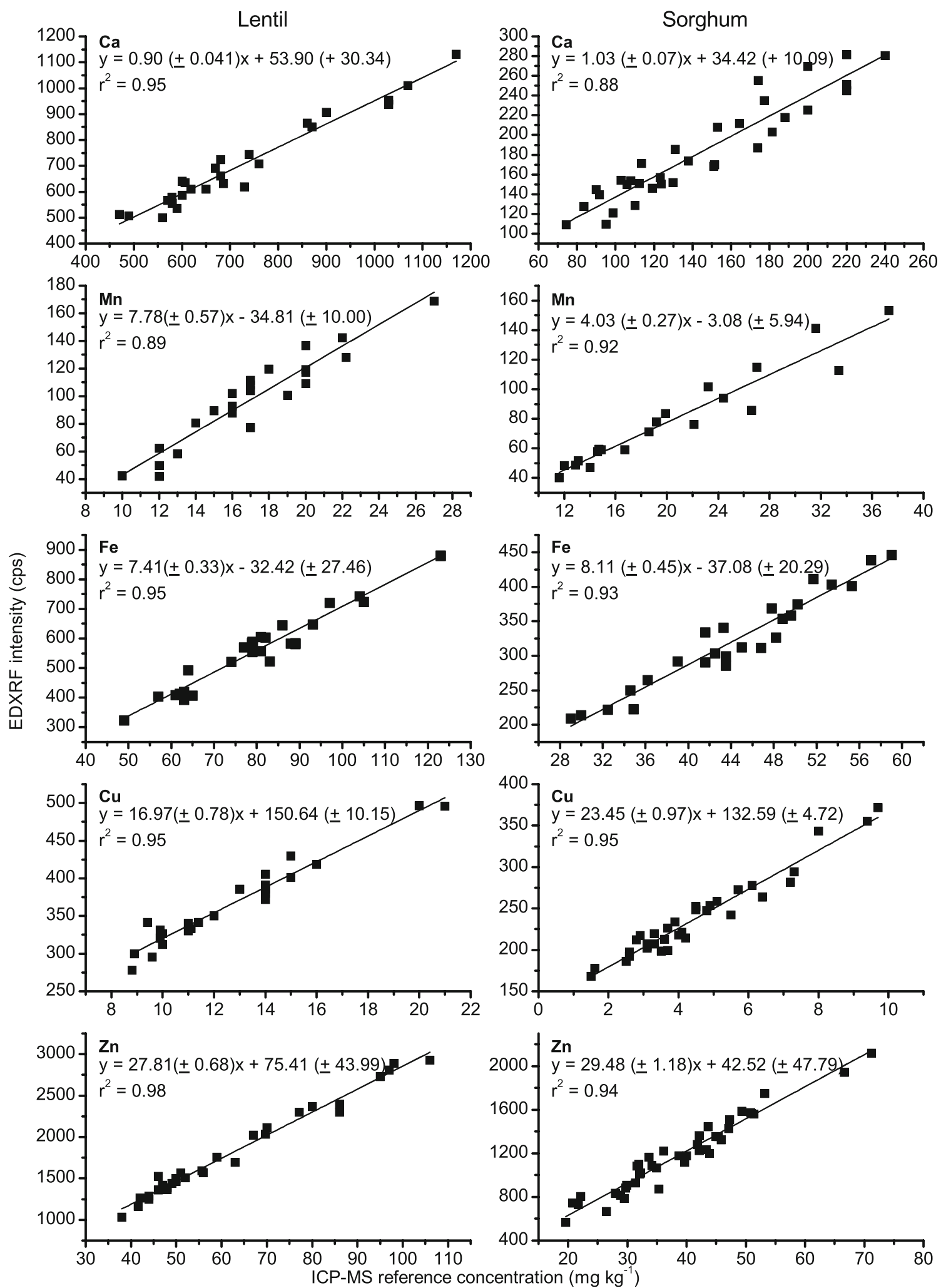

Fig. 1 EDXRF calibration for lentil (left) and sorghum (right) with duplicate ICP-MS reference analysis for $\mathrm{Ca}, \mathrm{Mn}, \mathrm{Fe}, \mathrm{Cu}$ and $\mathrm{Zn}$ 
Fig. 2 Effect of sorghum seed colour on correlation between EDXRF intensity and reference ICP-MS concentration. Red seeds are represented by black circle $(\bullet)$ and white seeds by grey triangle $(\triangle)$ and line of best fit shown in dashed black and solid grey for red and white seeds respectively

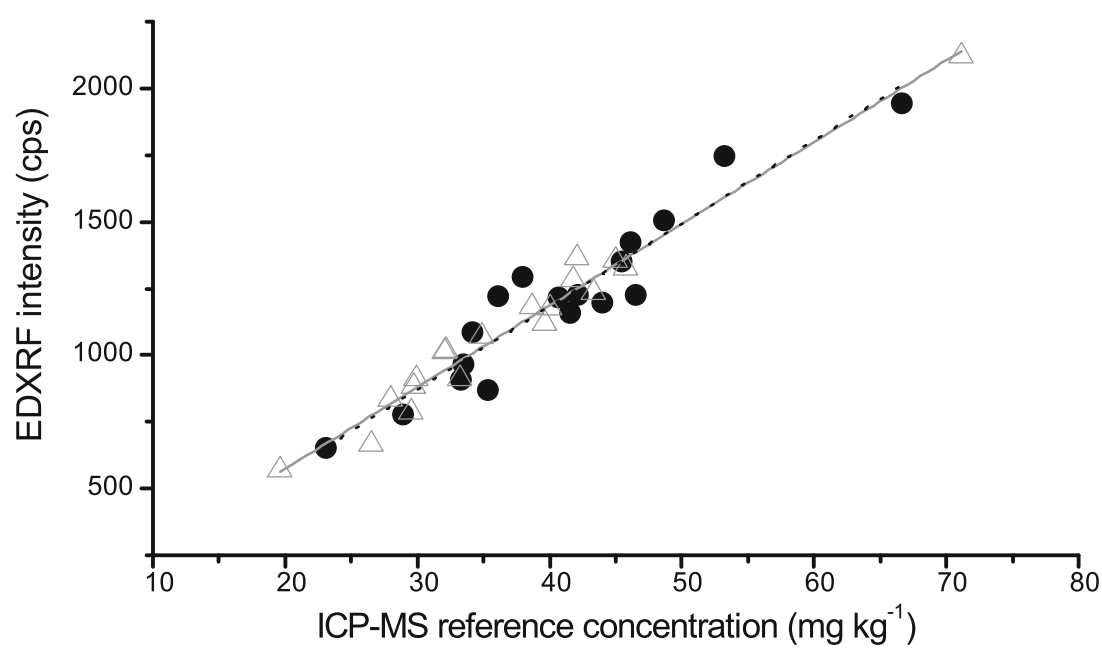

Fig. 4). The acquisition parameters used here are optimised for analysis of $\mathrm{Fe}$ and $\mathrm{Zn}$, however, our results demonstrate this method is also able to effectively quantify elements as light as $\mathrm{Ca}$. In order to create a robust calibration for each of the elements of interest, it is necessary to acquire a set of samples with a wide range of concentrations. Despite the focus on breeding for high $\mathrm{Fe}$ and $\mathrm{Zn}$ concentration, there was a suitable range of concentrations of the other elements in the HarvestPlus trial samples to develop robust calibrations for $\mathrm{Ca}, \mathrm{Mn}, \mathrm{Fe}, \mathrm{Cu}$ and $\mathrm{Zn}$.

$\mathrm{Ca}$ is the lightest of all the elements tested in this study. Generally, lighter elements are analysed under vacuum to minimise photon attenuation in the air atmosphere (Towett et al. 2016), requiring the preparation of pressed pellets. However, grinding, pressing and analysing under vacuum significantly adds to both the time and cost of this analysis, and is not suited to high throughput screening. It has been shown previously it is still possible to reliably detect $\mathrm{Ca}$ in plant samples under an air atmosphere with some sacrifice in detection limits (Towett et al. 2016). As Ca is a macronutrient present in relatively high concentrations in lentil and sorghum samples, the results presented here show it is still possible to adequately quantify $\mathrm{Ca}$ in both these crops. This effect of photon interaction with air is particularly evident in lighter photons and can be observed with the lighter elements generally showing weaker calibration and validation statistics. This photon interaction with air along with the low concentration of Mn in the samples is also the likely cause for the lower correlations observed between EDXRF and the reference ICP-MS analysis for this element.
EDXRF response is strongly impacted by the matrix of the sample. Guild et al. (2017) have previously shown the importance of crop specific calibrations to ensure optimum accuracy with EDXRF screening. As the biofortification program focusses on all seed coat colours of sorghum it was important to determine if the colour of the seed coat had any significant impact on the EDXRF response. A set of 18 red and 18 white sorghum samples were analysed with EDXRF to determine if the difference in the seed coat colour had a significant impact on the EDXRF response for $\mathrm{Zn}$. Comparing the EDXRF response versus ICP-MS reference concentration for the two different colours showed no significant difference $(p=0.81)$ in the correlation of EDXRF intensity vs. ICP-MS as shown in Fig. 2. Consequently, the EDXRF sorghum calibration was performed with a mix of all sorghum seed colours.

From the presented results it is evident the EDXRF validation data is not as strong and the \%RSD is higher in sorghum than lentil. This is likely due to a number of factors including the smaller range and lower concentration of analysed elements in the seed samples and the larger seed size resulting in a poorer representative sample in the XRF analysis window. Additionally, the RSD for the reference ICP-MS analysis was higher in sorghum than lentil, further compounding the possible calibration errors. Regardless of these factors, the EDXRF results are on average within $\pm 3 \mathrm{mg} \mathrm{kg}^{-1}$ of the ICP-MS results indicating that this method is suitable for screening these elements.

It is possible to improve the precision and accuracy of the analysis by grinding the samples to flour to improve sample homogeneity and packing density. However, as 

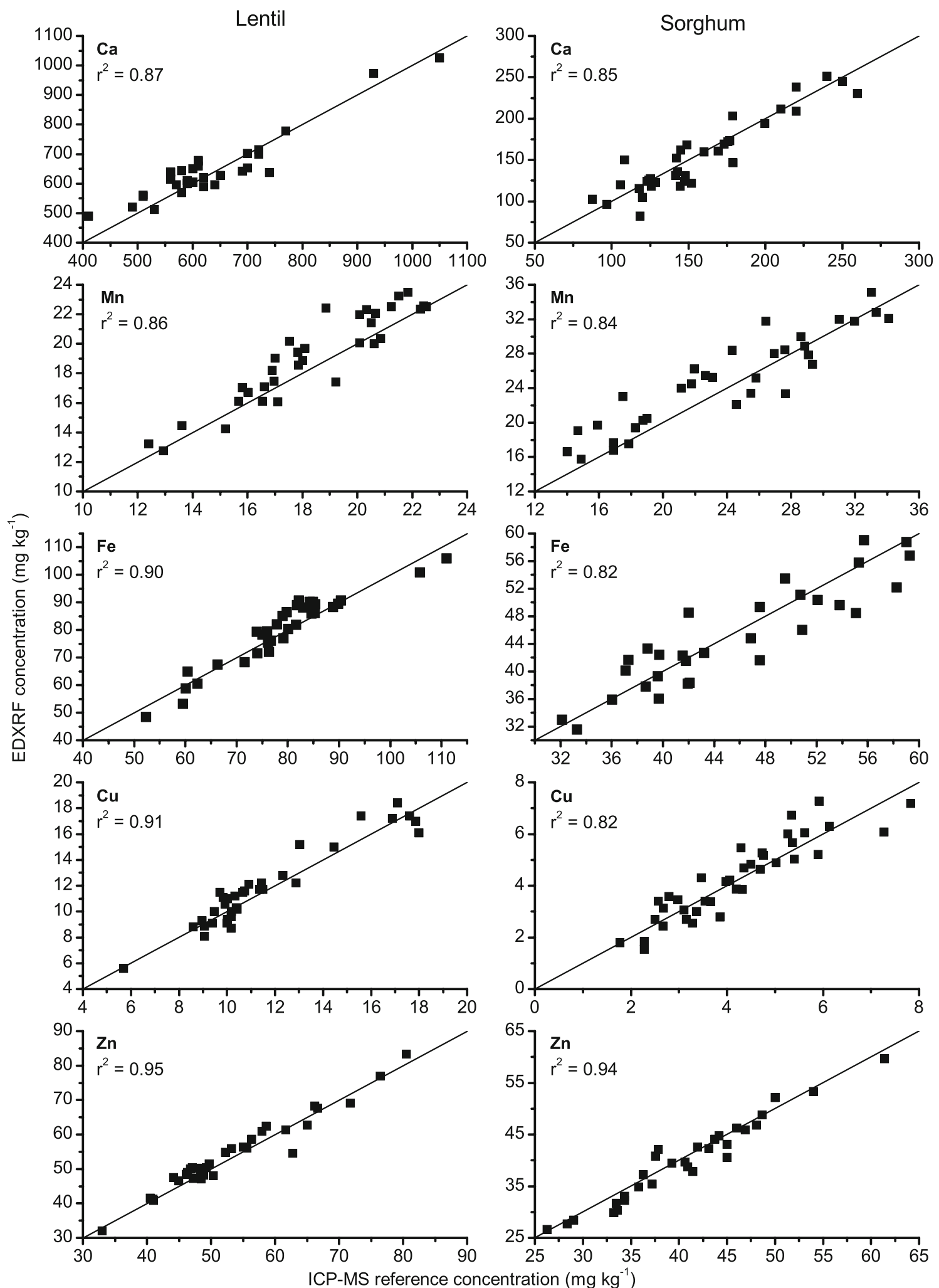

Fig. 3 Correlation between EDXRF analysis and reference ICP-MS analysis for $\mathrm{Ca}, \mathrm{Mn}, \mathrm{Fe}, \mathrm{Cu}$ and $\mathrm{Zn}$ in lentil (left) and sorghum (right) with $\mathrm{y}=\mathrm{x}$ represented by the solid line 
Table 3 Validation statistics for EDXRF analysis of lentil

\begin{tabular}{|c|c|c|c|c|c|c|}
\hline Method & Statistic & $\mathrm{Ca}$ & $\mathrm{Mn}$ & $\mathrm{Fe}$ & $\mathrm{Cu}$ & $\mathrm{Zn}$ \\
\hline \multirow[t]{2}{*}{ ICP-MS } & Range & $410-1050$ & $12.3-22.5$ & $52.3-111.0$ & $5.7-18.0$ & $41.0-80.5$ \\
\hline & Ave RSD & 2.6 & 2.3 & 1.2 & 2.1 & 2.3 \\
\hline \multirow[t]{6}{*}{ EDXRF } & $\mathrm{r}^{2}$ & 0.87 & 0.86 & 0.90 & 0.91 & 0.95 \\
\hline & SEP & \pm 50.8 & \pm 1.3 & \pm 4.0 & \pm 0.9 & \pm 2.1 \\
\hline & $95 \% \mathrm{CI}$ & \pm 17.1 & \pm 0.3 & \pm 1.3 & \pm 0.3 & \pm 0.8 \\
\hline & Bias & $+7.93^{\mathrm{a}}$ & +0.68 & $+1.22^{\mathrm{a}}$ & $+0.17^{\mathrm{a}}$ & $+0.82^{\mathrm{a}}$ \\
\hline & Ave SD & 24.6 & 0.87 & 3.5 & 0.67 & 1.9 \\
\hline & Ave RSD & 3.7 & 4.6 & 4.0 & 5.5 & 3.4 \\
\hline
\end{tabular}

${ }^{\text {a }}$ Bias not significantly different from zero at the $95 \%$ level according to paired t-test

All units presented as $\mathrm{mg} \mathrm{kg}^{-1}$, apart from RSD (\%) and $\mathrm{r}^{2}$

discussed previously (Paltridge et al. 2012a, b) the aim of this application within plant breeding is to enable rapid analysis with minimal sample preparation. Sample grinding has the potential to lead to contamination and significantly increases both the sample preparation time and the labour required for each analysis. The added benefit of analysing whole grain samples includes the ability to re-use the prepared XRF sample cup (not possible for flour samples) which further reduces cost per analysis along with sample handling and labour requirements and non-destructive analysis enables further analysis on the same sample. Additionally, the results from the whole grain analysis are more than suitable for screening as shown with results correlating strongly with the reference ICP-MS analysis and on average showing no significant difference (with the exception of $\mathrm{Mn}$ ) between the two analysis methods.

As with all EDXRF applications the precision and accuracy of the analysis is determined by the robustness of the initial calibration. This in turn is dependent on both the accuracy of the reference analysis and range of elements available within the crop of interest. This can be demonstrated with differences between the correlations for lentil and sorghum. In general, the range of elements in the calibration and validation sets is smaller and concentrations lower in sorghum. This and the larger seed size are the likely cause of the slightly weaker correlation statistics and higher RSD observed with the sorghum analyses.

\section{Conclusions}

Within the lentil and sorghum biofortification breeding programs, screening is required to identify those genotypes high in $\mathrm{Fe}$ and/ or $\mathrm{Zn}$. We have previously shown that EDXRF is the ideal tool for this analysis across many crops in the HarvestPlus program and here we

Table 4 Validation statistics for EDXRF analysis of sorghum

\begin{tabular}{|c|c|c|c|c|c|c|}
\hline Method & Statistic & $\mathrm{Ca}$ & $\mathrm{Mn}$ & $\mathrm{Fe}$ & $\mathrm{Cu}$ & $\mathrm{Zn}$ \\
\hline \multirow[t]{2}{*}{ ICP-MS } & Range & $87.5-260$ & $14.7-34.1$ & $32.1-63.0$ & $1.8-7.3$ & $26.3-61.4$ \\
\hline & Ave RSD & 2.5 & 3.5 & 4.7 & 2.8 & 3.3 \\
\hline \multirow[t]{6}{*}{ EDXRF } & $r^{2}$ & 0.85 & 0.84 & 0.82 & 0.82 & 0.94 \\
\hline & SEP & \pm 17.0 & \pm 2.6 & \pm 3.4 & \pm 0.6 & \pm 1.8 \\
\hline & $95 \% \mathrm{CI}$ & \pm 5.7 & \pm 0.81 & \pm 1.2 & \pm 0.20 & \pm 0.68 \\
\hline & Bias & $-2.95^{a}$ & +1.09 & $-0.52^{a}$ & $+0.07^{\mathrm{a}}$ & $-0.70^{a}$ \\
\hline & Ave SD & 8.4 & 2.1 & 3.0 & 0.42 & 1.9 \\
\hline & Ave RSD & 5.9 & 9.4 & 6.7 & 9.1 & 5.2 \\
\hline
\end{tabular}

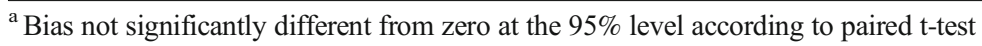

All units presented as $\mathrm{mg} \mathrm{kg}^{-1}$, apart from RSD (\%) and $\mathrm{r}^{2}$ 
Fig. 4 Example EDXRF spectrum of lentil sample

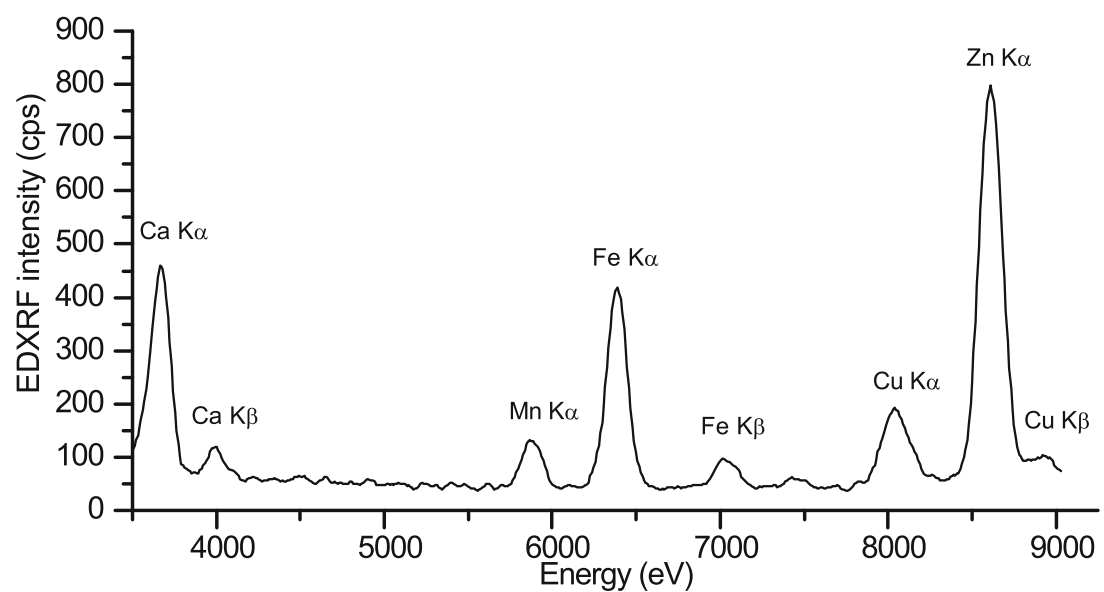

confirm this technique is also suitable for screening lentil and sorghum samples. EDXRF produces results comparable with ICP-MS but with the benefit of minimal sample preparation, non-destructive rapid analysis, low consumable costs and userfriendly techniques. A considerable benefit of EDXRF analysis is the low cost per sample with preparation of sample cups the only consumable for this analysis ( $\sim$ US 0.15 per sample). The rapid analysis enables 25 samples to be scanned per hour (30 s analysis time and remaining sample movement/ handling time). Furthermore, as grinding of samples is not required, labour costs are minimal for this analysis. Here we have demonstrated EDXRF can also be used to simultaneously determine the concentration of $\mathrm{Ca}, \mathrm{Mn}$ and $\mathrm{Cu}$ which may be beneficial for expanded breeding programs in the future. These results have shown that it is possible to expect (with $95 \%$ confidence) the EDXRF analysis will be $< \pm 1.3 \mathrm{mg} \mathrm{kg}^{-1}$ of ICP-MS for $\mathrm{Mn}, \mathrm{Fe}, \mathrm{Cu}$ and $\mathrm{Zn}$ and $< \pm 15 \mathrm{mg}$ $\mathrm{kg}^{-1}$ for $\mathrm{Ca}$ in lentil and sorghum crops.

Acknowledgements This study was made possible with support from HarvestPlus. HarvestPlus' principal donors are the UK Government; the Bill \& Melinda Gates Foundation; the US Government's Feed the Future initiative; Global Affair Canada; the European Commission; the Children's Investment Fund Foundation, and donors to the CGIAR Research Program on Agriculture for Nutrition and Health (A4NH). HarvestPlus is also supported by the John D. and Catherine T. MacArthur Foundation. We would like to thank our collaborators at BARI, ICARDA and ICRISAT for kindly providing the seeds.

Funding This research was funded by HarvestPlus.

Data availability Not applicable.
Code availability Not applicable.

\section{Declarations}

Conflicts of interest The authors have no conflicts of interest to declare.

Ethics approval Not applicable.

Consent to participate Not applicable.

Consent for publication All authors consent to publication of this manuscript.

Open Access This article is licensed under a Creative Commons Attribution 4.0 International License, which permits use, sharing, adaptation, distribution and reproduction in any medium or format, as long as you give appropriate credit to the original author(s) and the source, provide a link to the Creative Commons licence, and indicate if changes were made. The images or other third party material in this article are included in the article's Creative Commons licence, unless indicated otherwise in a credit line to the material. If material is not included in the article's Creative Commons licence and your intended use is not permitted by statutory regulation or exceeds the permitted use, you will need to obtain permission directly from the copyright holder. To view a copy of this licence, visit http://creativecommons.org/licenses/by/4.0/.

\section{References}

Bouis HE, Saltzman A (2017) Improving nutrition through biofortification: A review of evidence from HarvestPlus, 2003 through 2016. Global Food Secur 12:49-58. https://doi.org/10.1016/j.gfs.2017.01.009

Bouis HE, Eozenou P, Rahman A (2011) Food prices, household income, and resource allocation: socioeconomic perspectives 
on their effects on dietary quality and nutritional status. Food Nutr Bull 32:S14-S23. https://doi.org/10.1177 $/ 15648265110321 \mathrm{~s} 103$

Gorstein J, Sullivan K, Parvanta I, Begin F (2007) Indicators and methods for cross-sectional surveys of vitamin and mineral status of populations. The Micronutrient Initiative (Ottawa) and the Centers for Disease Control and Prevention (Atlanta), 53

Guild GE, Paltridge NG, Andersson MS, Stangoulis JCR (2017) An energy-dispersive X-ray fluorescence method for analyzing $\mathrm{Fe}$ and $\mathrm{Zn}$ in common bean, maize and cowpea biofortification programs. Plant Soil 419:457-466. https://doi.org/10.1007/s11104-017-3352-4

HarvestPlus (2014) Biofortification Progress Briefs; Brief 9, 19. Available at https://www.harvestplus . org/sites/default/files/Biofortification_Progress_Briefs August2014_WEB_0.pdf. Accessed 20 Öt 2020

Knez M, Tako E, Glahn RP, Kolba N, De Courcy-Ireland E, Stangoulis JCR (2018) Linoleic acid:Dihomo- $\gamma$-linolenic acid ratio predicts the efficacy of Zn-biofortified wheat in chicken (Gallus gallus). J Agric Food Chem 66:1394-1400. https://doi.org/10.1021/acs.jafc.7b04905

Paltridge NG, Milham PJ, Ortiz-Monasterio JI, Velu G, Yasmin Z, Palmer LJ, Guild GE, Stangoulis JCR (2012a) Energydispersive X-ray fluorescence spectrometry as a tool for zinc, iron and selenium analysis in whole grain wheat. Plant Soil 361:261-269. https://doi.org/10.1007/s11104-012-1423-0

Paltridge NG, Palmer LJ, Milham PJ, Guild GE, Stangoulis JCR (2012b) Energy-dispersive X-ray fluorescence analysis of zinc and iron concentration in rice and pearl millet grain. Plant Soil 361:251-260. https://doi.org/10.1007/s11104011-1104-4

Perring L, Andrey D (2003) ED-XRF as a tool for rapid minerals control in milk-based products. J Agric Food Chem 51:42074212. https://doi.org/10.1021/jf034158p
Pfeiffer WH, McClafferty B (2007) HarvestPlus: Breeding crops for better nutrition. Crop Sci 47:S88-S105. https://doi. org/10.2135/cropsci2007.09.0020IPBS

Sosa P, Guild G, Burgos G, Bonierbale M, zum Felde T (2018) Potential and application of X-ray fluorescence spectrometry to estimate iron and zinc concentration in potato tubers. $\mathrm{J}$ Food Compos Anal 70:22-27. https://doi.org/10.1016/j. jfca.2018.03.004

Stangoulis J, Sison C (2008) Crop sampling protocols for micronutrient analysis. Harvest Plus Tech Monogr Ser 7:1-20

Towett EK, Shepherd KD, Drake BL (2016) Plant elemental composition and portable X-ray fluorescence (pXRF) spectroscopy: quantification under different analytical parameters. X-Ray Spectrom 45:117-124. https://doi.org/10.1002 /xrs.2678

UNICEF (2020) The State of Food Security and Nutrition in the World 2020. Transforming food systems for affordable healthy diets. Rome FAO. Available at http://www.fao. org/documents/card/en/c/ca9692en. Accessed 20 Oct 2020

Welch RM, Graham RD (2005) Agriculture: the real nexus for enhancing bioavailable micronutrients in food crops. J Trace Elem Med Biol 18:299-307. https://doi.org/10.1016/j. jtemb.2005.03.001

Wheal MS, Fowles TO, Palmer LT (2011) A cost-effective acid digestion method using closed polypropylene tubes for inductively coupled plasma optical emission spectrometry (ICP-OES) analysis of plant essential elements. Anal Methods 3:2854-2863. https://doi.org/10.1039/c1ay05430a

Publisher's note Springer Nature remains neutral with regard to jurisdictional claims in published maps and institutional affiliations. 